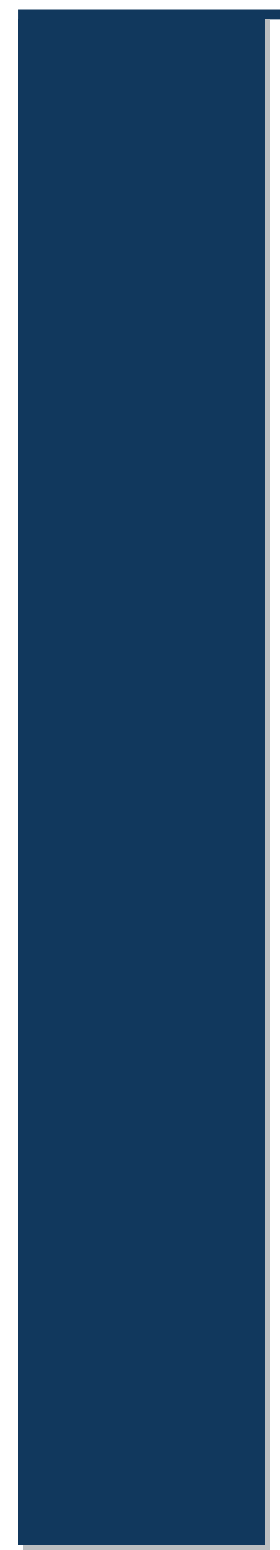

\title{
DA MISOGINIA À METÁFORA DAS CAMADAS
}

\author{
Benedito Costa Neto Filho ${ }^{1}$ \\ João Victor Ponciano ${ }^{2}$
}

\section{RESUMO}

O presente trabalho busca evidenciar um grave problema que pode ser mensurado nas sociedades atuais: refere-se ao mundo dominado por discursos masculinistas, eurocêntricos e pelo neoliberalismo do capitalismo tardio. Tais discursos culminam nas exclusões sobre a situação da mulher, que por vezes é rebaixada pelo "simples fato de ser mulher", em condição de subalternidade em relação aos homens. A falta de publicações de/sobre/para mulheres (ou o modo como são disseminadas), no mercado editorial, por exemplo, revela-se apenas como um dos inúmeros índices que desenham uma triste realidade para a situação da mulher. As dominações masculinas nos espaços de poder posicionam as mulheres em situação de inferioridade. Esta lógica acaba dando base ao falso direito dado aos homens de tratá-la de modo objetificado. Por isso, situações graves como o feminicídio levam a uma determinada parcela da sociedade à indiferença, uma vez que o sistema como um todo (o direito, a medicina, a mídia, o ensino) naturaliza qualquer ato opressivo em relação à mulher. $A$ morte de mulheres, o discurso de ódio, a desigualdade salarial, a falta de espaços nas instituições religiosas, no esporte, na academia e até mesmo o uso da língua do dia a dia (com frases como "isso não é coisa de mulher") são justificadas por uma espécie de regime de verdade, ditada pelos homens. A fim de apontarmos uma possibilidade de investigação dessa realidade, de maneira mais incisiva, a respeito da situação das mulheres, como uma ferramenta da ética da pesquisa, e de modo a empreendermos ações de desconstrução de um regime opressor, buscaremos, a partir da pensadora argentina Florencia Luna (que produziu um texto que traz o conceito de "metáfora das camadas", a respeito dos graus de vulnerabilidade em que se encontram diversos sujeitos sociais), trazer considerações sobre a situação da mulher (num painel

\footnotetext{
1 Mestre e Doutor em Literatura, com ênfase na investigação da relação entre Literatura e História pela Universidade Federal do Paraná. Atua como professor na área de língua e de linguagem. Autor de vários livros e catálogos na área de crítica de arte contemporânea. E-mail: costanetobenedito@gmail.com.

2 Mestre em Filosofia pela Pontifícia Universidade Católica. Graduado em filosofia pela Faculdade Vicentina. Membro do GT Filosofia e Psicanálise da Associação Nacional de Pós-Graduação em Filosofia (ANPOF). Coordenador e fundador do grupo de estudos Filosofia em Perspectiva. E-mail: jvponcianopucpr@gmail.com
}

Rev. Omni. Sap., Mossoró, v.1, n.2, p. 70-81, dez. 2021. DOI: 10.29327/240437.1.2-4 | ISSN: 2764-3239 
provisório e muito aquém da realidade da mulher). Entendemos que a "metáfora das camadas" possa ser usada tanto por pesquisadores quanto por aqueles que lidam com ações práticas em relação à situação da mulher, seja a mulher negra periférica, a mulher branca da alta sociedade, a mulher trans, a quilombola, a mãe solteira, dentre outras, ou seja, qualquer mulher que, num certo momento da vida, esteja com uma ou mais camadas de vulnerabilidade.

Palavras-Chave: Mulheres; Metáfora das camadas; Violência; Vulnerabilidade; Florencia Luna.

\title{
FROM MISOGYNY TO THE METAPHOR OF LAYERS
}

\begin{abstract}
The present work seeks to highlight a serious problem that can be measured in today's societies: it refers to the world dominated by masculinist, Eurocentric discourses and the neoliberalism of late capitalism. Such speeches culminate in exclusions regarding the situation of women, which is sometimes demoted by the "simple fact of being a woman", in a condition of subordination in relation to men. The lack of / about / for women publications (or the way they are disseminated), in the publishing market, for example, reveals itself only as one of the countless indexes that draw a sad reality for the situation of women. Male domination in the spaces of power places women in an inferior position. This logic ends up giving basis to the false right given to men to treat it objectively. For this reason, serious situations such as femicide lead indifference to a certain part of society, since the system as a whole (law, medicine, the media, education) naturalizes any oppressive act towards women. The death of women, hate speech, wage inequality, the lack of spaces in religious institutions, sports, the academy and even the use of everyday language (with phrases like "this is not a woman's thing") are justified by a kind of regime of truth, dictated by men. In order to point out a possibility of investigating this reality, in a more incisive way, regarding the situation of women, as a tool of research ethics, and in order to undertake actions to deconstruct an oppressive regime, we will seek, from the thinker Argentine Florencia Luna (who produced a text that brings the concept of "metaphor of layers", regarding the degrees of vulnerability in which different social subjects are found), bring considerations about the situation of women (in a provisional panel and far from reality of the woman). We understand that the "layer metaphor" can be used both by researchers and by those who deal with practical actions in relation to the situation of women, be it the peripheral black woman, the white woman of high society, the trans woman, the quilombola, the single mother, among others, that is, any woman who, at a certain point in life, has one or more layers of vulnerability.
\end{abstract}

Keywords: Women; Metaphor of layers; Violence; Vulnerability; Florencia Luna. 


\section{INTRODUÇÃO}

No mudo todo "surgem" produções culturais que abordam a situação da mulher: no mundo eslavo, por exemplo, começamos a ter contato com obras de reconhecidas escritoras, como Ludmila Ulytskaia, que tem um tratamento muito especial para a situação da mulher comum russa, ou ainda a laureada com o Prêmio Nobel Svetlana Alexijevich, que escreveu um contundente livro sobre a situação na mulher na guerra, A guerra não tem rosto de mulher. No mundo árabe, a despeito de uma imensa dificuldade de publicações de livros sobre a condição da mulher, temos o trabalho corajoso e pioneiro de Nawal el Saadawi, que escreveu um requintado livro em que ficção e reportagem dão-se as mãos (Woman at point zero). Ao falar de uma presidiária, ela trata de todo um mundo de injustiças sofrido por mulheres árabes e não árabes no mundo de maioria islâmica. Na África, temos Paulina Chiziane, que, com seu Niketche, constrói uma realidade quase inverossímil sobre a situação da mulher moçambicana, dizendo-se uma contadora de histórias e não uma romancista. No mundo caribenho, Françoise Ega (Cartas a uma negra) faz eco a Maria Carolina de Jesus, a escritora brasileira, para quem escreveu cartas que nunca foram enviadas, mas com quem divide um mundo de injustiças e subalternidade. E haverá escritoras mais famosas, como Margaret Atwood, ou menos famosas, menos desejadas pelo mercado editorial, que verão a mulher, a situação da mulher, como objeto de investigação intelectual e artística.

Caberia uma explicação às aspas colocadas no verbo "surgir" da primeira linha. Em verdade, elas não surgem; elas sempre existiram. O que ocorre, aqui, no Caribe, na África, no sudoeste asiático ou nos países ricos (do Norte Global ou de países que estão no Sul Global, mas que fazem parte da lista de países mais ricos do planeta) é a dificuldade que há de tais produtos culturais conseguirem chegar ao grande mercado. Ou são editoras grandes que acabam cedendo espaço em sua grade geralmente masculina - e branca - ou são editoras menores que escolhem publicar obras de escritoras mulheres, justamente pela falta de espaço que há no mercado, sofrendo todas as dificuldades possíveis, da edição à presença nas estantes de grandes livrarias ou sites de vendas. Haveria falta de interesse no mercado sobre as discussões feministas (ou produzidas "por mulheres")? Não. A pergunta é retórica. A própria fama alcançada por outras produções culturais, como é o caso das séries, hoje tão acessíveis em serviços de streaming, explica o interesse do mercado na abordagem sobre a situação da mulher: são exemplos disso Alias Grace, que trata diretamente da situação da mulher ou ainda Sense8, que tem como um dos assuntos a situação das mulheres, incluindo as mulheres trans.

Mas então o que haveria, ou melhor, o que explicaria a falta de produtos culturais sobre a mulher, produzido por mulheres e, sem esgotar a questão, para mulheres? Trata-se de três situações diferentes, mas não excludentes. A falta de publicações de/sobre/para mulheres (e também o modo como se dão, quando existem, o que vem a ser outra questão, principalmente no caso de "para mulheres") no mercado editorial é apenas um dos inúmeros sintomas que desenham uma triste realidade para a situação da mulher. O mercado editorial espelha a dilatada realidade social em que 
a mulher é presente (como produtora ou consumidora), mas não tem voz ativa. $E$ tal situação é ainda mais grave para determinadas mulheres, como se verá em seguida.

Veja-se a representação da mulher na mídia e como os discursos feministas/sobre o feminino são escamoteados e vendidos distorcidos em novelas, em propagandas, no cinema, em programas de auditório, na vida política, no mundo jurídico, no universo médico, dentro e fora das universidades etc. Como não seria possível listar todas as situações aqui, partamos de uma pesquisa feita pela pesquisadora Juliana Bertholdi sobre a situação das mulheres nas empresas transnacionais: a autora mostra como a ação das empresas estrangeiras, em vez de auxiliar na luta pela igualdade entre homens e mulheres, agrava a situação de países periféricos, como os da América Latina. A par com isso, está a total e absoluta falta de programas governamentais que amparem a mulher trabalhadora (BERTHOLDI, 2021). Quando há programas específicos, eles não são elaborados de acordo com as diferenças entre as mulheres, são genéricos no tocante à expressão "da mulher" e ainda são mais perversos quanto à situação da mulher preta/negra, da mulher indígena, da mulher quilombola, da mulher portadora de deficiência e da mulher LBTI. Ou seja, a situação é muito mais grave do que discutir uma questão genérica; a questão é discutir, problematizar e encontrar saídas para a diversidade do "ser mulher".

Este breve o texto mostra algumas possibilidades de se problematizar a questão, mostrando ferramentas de discussão possíveis. Está dividido em três partes: a introdução, encerrada aqui, uma breve abordagem sobre o sentido de "naturalidade" no que tange a questões da mulher e, por fim, a apresentação do raciocínio de Florencia Luna.

\section{SOBRE O NATURAL E O COTIDIANO}

Bourdieu, no já clássico $A$ dominação masculina, perguntava-se no preâmbulo como determinadas situações podem ser consideradas "aceitáveis" ou "até mesmo naturais", sendo que "cinco minutos de circulação automobilísticas ao redor da Praça da Bastilha" já mostrariam diversos absurdos (BOURDIEU, 2012, p.7). Ele não falava de um passeio de carro por uma cidade norte-africana e sim da capital da França. De lá para cá, houve avanços consideráveis nessa crítica, e autoras do mundo todo investigam em seus respectivos universos o porquê de ainda a situação da mulher, na maioria dos lugares, ser tida como natural e aceitável, mesmo quando ela é morta por um companheiro que terá todo o amparo da estrutura masculinista da justiça, da imprensa, de partidos políticos, da igreja.

Hoje, autoras como Silvia Federici demonstraram, "a partir de uma análise histórica, que a discriminação contra a mulher na sociedade capitalista não é legado de um mundo pré-moderno, mas sim uma formação do capitalismo". Indo muito mais além, a pesquisadora afirma que tal formação foi "construída sobre diferenças sociais existentes para cumprir novas funções sociais" (FEDERICI, 2017, p.11). Tal estudo, na esteira dos discursos e teorias da Nova História, ecoa trabalhos anteriores (ou coetâneos), como os de Natalie Zemon Davis, em que a historiada demostra que mulheres donas de negócios e condutoras de seu destino, no meio de uma sociedade 
patriarcal, existem há séculos. Veja-se o caso de Glikl bas Judah Leib, que em pleno século XVII europeu, assumiu os negócios da família e cuidou de uma extensa prole (DAVIS, 1997, p. 15). Esta, demostra a ancestralidade da situação da mulher como protagonista de sua vida ( $\mathrm{sim}$, com diferenças brutais de temporalidade) e aquela como o mundo moderno carregou junto "novas funções sociais para as já existentes.

Como a teoria da História já mostrou, a escrita da História "incorporou" corpo e mentes de mulheres. A todo tempo, vemos "resgates" de mulheres esquecidas na História, seja uma matemática da Antiguidade, como Hypatia de Alexandria, seja uma doutora da Igreja Católica Romana, como Hildegarda, ou ainda uma poeta como Faltonia Proba. Aqui caberia uma menção ao levantamento ao modo de um dicionário - e verbetes - de Marcos Roberto Nunes Costa e Rafael Pereira Costa, em que mostram quantas mulheres ficaram à margem das pesquisas dos historiadores e historiadoras, da Antiguidade tardia à Renascença. Trata-se de Mulheres intelectuais na Idade Média: entre a medicina, a história, a poesia, a dramaturgia, a filosofia, a teologia e a mística. Algo muito similar e ainda no mesmo terreno ocorre na crítica das artes plásticas, quando se trata de uma pintora como Sofonisba Anguissola, por exemplo, que tem sido bastante citada como exemplo de mulher que ficou à margem da História. Tais levantamentos são indiscutivelmente importantes. O problema é quando caem na grande rede do capitalismo tardio e se transformam em produtos de consumo, tornando-se elementos exóticos, sexualizados ou explorados, simplesmente, pela superfície. Na grande batalha discursiva social, algumas mulheres "resgatadas" da História tornam-se personagens de filmes, romances e até propagandas, dentro de um cenário em que o empoderamento é apenas mais um penduricalho brilhante das deturpações do mercado, no neocolonialismo e do neoliberalismo.

Outras áreas do saber, principalmente no tão próximo de nós século $X X$, incorporaram corpo e mentes femininas/de mulheres: a Linguística, por exemplo, passou a fazer recortes em que a mulher (num sentido mais figurado do que qualquer outro, sem grandes diferenciações transversais) passou a ser um elemento de recorte de pesquisa. Pensemos no caso da Sociolinguística, em que "gênero" (ainda que num sentido binomial, homem $x$ mulher) se tornou um recorte de suma importância, afinal o modo como homens e mulheres utilizam a língua não é o mesmo. Ainda na Linguística, área recentes do saber linguístico, como a $A D$ - Análise do discurso, investigam o discurso/fala/lugar de fala da mulher através de uma perspectiva que dá as mãos à teoria da História, à Sociologia, às áreas "psi". Não obstante o esforço hercúleo e erudito dessa jovem área, ainda é esnobada por muitas outras, e isso ocorre mesmo dentro da academia, local em que diferentes saberes deveriam ser bem-vindos. Na Medicina, houve avanços no estudo da situação da mulher, com toda uma taxonomia (em sentido foucaultiano) particular para as "questões femininas", "questões da mulher", "medicina voltada para o corpo da mulher". No Direito, houve avanços significativos, como no caso brasileiro em que o feminicídio se tornou uma tipificação criminal e não um homicídio comum, embora ainda haja terreno a ser conquistado, uma vez que o Direito pode pregar algo e não o seguir na prática, se as investigações, o processo, o julgamento, a pena e o cumprimento dessas não estiverem à altura do texto legal, caso em que o texto legal será apenas um texto que maquia a realidade sensível 
das mulheres, restando um monte de tinta sobre papel branco. E outros exemplos caberiam aqui: a Economia, os estudos da religião, as pesquisas científicas das áreas exatas, as áreas de gestão. Convém anotar algo extremamente importante: nenhuma dessas áreas é estanque, pois de um modo ou de outro elas dialogam, mesmo que atravessando pontes muito frágeis para que toquem os dedos.

Mas talvez nenhuma outra área do saber como a sociologia tenha trazido tanta luz sobre a situação das mulheres. Falamos em Sociologia como uma área do saber que caberia numa definição estreita, mas não. A Sociologia, seria melhor dizer, em todas as suas vertentes, a política, a feminista, a dos estudos queer, a urbana, a rural, a marxista, a psicanalítica. É dessas áreas que nos chegam vozes que discutem a situação da mulher numa frente muito ampla, é dessa área que temos vozes do mundo todo, sejam já as pesquisadoras mais conhecidas e divulgadas, como Judith Butler, quanto pensadoras já conhecidas no exterior e que ganham traduções cada vez mais bem cuidadas e divulgadas no Brasil, como Françoise Vergès, sejam aquelas que ainda esperam pela divulgação maior do seu trabalho em português, como Florencia Luna e Oyèrónkẹ Oyěwùmí. Mas aí chegamos a uma curva muito fechada e perigosa: tantas áreas e tantas situações do saber trazem as discussões de que precisamos, sem as quais não há avanços (políticos, jurídicos, artísticos etc.), porém, o modo como o mercado as recebe falseia, muitas vezes, a verdadeira situação da mulher, apontando situações em que as respostas aparentam ser plausíveis, fáticas, tangíveis. Ver, por exemplo, mulheres dirigindo trens imensos ou caminhões em atividades extrativistas, numa matéria de jornal televisivo, pode trazer uma sensação de igualdade, empoderamento e inclusão. Não é falso, frise-se: mulheres demoraram séculos ou décadas para terem o direito de um trabalho considerado "masculino". No entanto, essas imagens tão amadas por editores de grandes jornais televisivos mascaram realidades pavorosas da mulher trabalhadora num universo dominado por homens: o salário mais baixo, a violência sexual, moral e simbólica, a falta de uma política trabalhista que lhes dê apoio e amparo do caso de gravidezes e situações de saúde da mulher etc. Ver mulheres dirigindo grandes produções fílmicas não lhes dá o lugar merecido no panteão dos vitoriosos. Para não colocarmos tudo em termos financeiros - embora o valor recebido por mulheres diretoras e atrizes seja menor que o dos homens, com raríssimas exceções, e isso é um problema, sim -, temos as premiações, os títulos, o respeito social e assim por diante, e temos ainda o terreno, ainda dominado pelo poder machista, masculinista, androcêntrico, que dificulta sobremaneira abordagens feitas por mulheres, sobre mulheres e para mulheres. Basta olhar para as listas de premiações que inundam a internet para vermos o quão distante as mulheres estão em relação aos homens. Se isso ocorre numa indústria poderosa de países do Norte Global, e se isso continua ocorrendo em grandes empresas, e se isso ocorre em países ditos democráticos, em "Estados democráticos de Direito" ricos, a situação em países periféricos e mesmo nas margens das grandes cidades dos países ricos, para as mulheres subalternizadas, é algo desesperador. E tal situação ecoa e se faz sentir nas câmaras de vereadores, nas cadeiras dos deputados estaduais e federais, no senado e nos comandos de países mundo afora, com exceções a contar nos dedos. O Brasil, por exemplo, teve apenas uma mulher 
presidente - e ela foi deposta.

Pensemos que, sem o avanço dos grandes e sérios estudos sobre a situação das mulheres, a situação seria muito pior. Sem a luta de entidades feministas, o Direito ainda apoiaria homens que matam as esposas "em defesa da honra". No entanto, há muito território a ser vencido, numa luta desigual, sem paridade de armas, e ainda agravada muitíssimo com o avanço dos discursos fascistas que vemos pipocar em diversas partes do Globo, em especial no Brasil. De nada, ou muito pouco, adianta o estudo de campo, de observação, intuitivo, se a mulher continua objeto sexual, chamariz, ou subalternizada na mídia, no cinema, na televisão e hoje na internet. A pesquisadora bell hooks, por exemplo, mostra como imensa parte dos expectadores compra gato por lebre no tocante à representação da mulher. Ela cita o estudo de Gail Faurshou, chamado A moda e a lógica cultural da pós-modernidade, em que a autora demonstra o que ocorre com o corpo feminino negro, em particular:

\begin{abstract}
[tal] mudança cultural possibilita que os corpos das mulheres negras sejam representados em certos domínios do "belo" onde eles já tiveram sua entrada recusada, como nas revistas sofisticadas de moda. Reinseridos como espetáculo, mais uma vez em exibição, os corpos das mulheres negras aparecem nessas revistas, não como registro da beleza da pele escura (...) mas para chamar a atenção para outras preocupações. Eles parecem representar uma antiestética, que zomba da verdadeira ideia de beleza (HOOKS, 2019, p. 145).
\end{abstract}

E a preocupação é a venda de outros produtos, inclusive não direcionados à comunidade negra. Marcas grandes e pequenas utilizam-se do mesmo artifício, colocando em suas pautas questões de verdadeira e suma importância, mas ali, de modo equivocado, por vezes cruel. Longe de minimizar o sofrimento da população negra, algo similar ocorre com as mulheres de forma geral, que ganham protagonismo em novelas, filmes, seriados, romances, peças de teatro, exposições artísticas, mas basta um mero olhar para o modo como são representadas, as listas de artistas nos museus e galerias de arte, a construção de personagem em novelas e seriados etc., para a constatação irrefutável: ali há um ser que não é real em hipótese alguma - é a leitura do ser mulher, feita por homens ou mulheres em completa dissonância com as grandes causas e a real situação da mulher no mundo. Um terrível e banal exemplo disso tudo é a nudez feminina, que continua um produto caro ao mercado.

Algumas categorias do pensamento são um problema sem pacificação. Sabemos disso, precisamos lidar com isso e encontrar respostas para crises desse tipo, principalmente quando não temos (ainda) vocabulário próprio para discutir um tema. Sloterdjik parte do princípio que lidamos com "sociedade", por exemplo, como lidamos com um elemento mítico. Ele adjetivou o vocábulo "sociedade" como algo "suspeito", mas lembra que "sociedade" também é um "animal fantástico e real" (SLOTERDIJK, 2017, p. 13).

Então, caberia esta colocação antes de fecharmos este trecho com o pensamento da pesquisadora húngara, de linha lukacsiana, Agner Heller. Em O Cotidiano e a História, Heller conceitua "cotidiano", "preconceito", "indivíduo" e "comunidade". 
Dando ênfase ao conceito de "preconceito", aqui, e fazendo uma ponte possível com o raciocínio de Bourdieu, citado acima, Heller, critica o que chama de "uma categoria do pensamento e do comportamento cotidiano" (HELLER, 1992, p. 43), o preconceito. A pesquisadora intui que a ultragenerização é inevitável na vida cotidiana, uma vez que não nos empenhamos em analisar todas as atividades cotidianas baseados em conceitos fundados cientificamente:

[...] o grau de ultragenerização nem sempre é o mesmo. A rigidez das formas de pensamento e comportamento cotidianos é apenas relativa, ou seja, pode se modificar lentamente na atividade permanente e, com efeito, geralmente se modifica. Toda generalização é um juízo provisório ou uma regra provisória de comportamento: provisória porque se antecipa à atividade possível e nem sempre, muito pelo contrário, encontra confirmação no infinito processo da prática. (HELLER, 2017, p. 44, grifo da autora).

O indivíduo que vive nessa sociedade, de conceito provisório também, passa por processos facilitadores, muitas vezes mediados pela mídia, pelo ensino formal, pelas igrejas, pelo contato cotidiano com o outro, pelas leituras - e hoje pela incalculável quantidade de informações a que pode acessar de onde estiver, bastando um telefone móvel e uma rede. Ele "aceita" como "natural" e "cotidiana" a violência contra a mulher, o que aparece na língua (de forma "natural", em piadas, brincadeiras, abordagens de teor sexual), toques, no dia a dia e, em outras esferas, na violência física e moral, na diferença salarial, no rebaixamento, no mansplaining, nas ofensas de trânsito, no silenciar político etc.

Então até aqui temos: a) uma sociedade em que muitas vezes o horror é algo natural (Bourdieu); b) uma sociedade de sentido provisório, pois a palavra em si, embora precisemos dela, não comporta a complexidade de seu todo (Sloderdijk); c) a falsidade/equívoco na utilização das questões de mulheres (negras, em particular para hooks, mas, por extenção, das brancas, indígenas, quilombolas, portadoras de deficiência, LGBTI, solteiras, dentre outras) pela grande mídia; d) a vivência de processos facilitadores que permitem uma ultragenerização, que torna nossas atividades "naturais" e sem "investigação mais profunda" (Heller). Deveríamos somar a esses pontos, o pensamento de Federici e o de Françoise Vergès: a situação da mulher é grave no capitalismo tardio e no universo (neo)colonial ainda pior.

\section{A TEORIA DAS CAMADAS E UM CONCEITO PARA VULNERABILIDADE}

Diante desse quadro: a) do avanço das pesquisas e das lutas contrárias a esses avanços, como o aumento de partidos políticos de extrema direita; b) a situação de falsidade que ocorre com a representatividade, o empoderamento e a inclusão, quando o mercado comum ao capitalismo tardio se apodera de discursos de luta para transformá-los em produto; c) do cenário de franco crescimento de discursos e práticas conservadoras, como o caso das igrejas neopentecostais; d) dos novos estudos de transversalidade e intersecção; e) das próprias lutas internas no interior de 
uma vasta rede de saberes sobre o "ser mulher"; f) do perigo da generalização quando usamos vocábulos de acepção muito vaga ou extensa, como "sociedade", trazemos aqui o pensamento de Florencia Luna. Dentre tantos, um possível.

A teórica argentina escreveu um texto em que traz o conceito de uma "metáfora das camadas", em que investiga a noção de vulnerabilidade. Primeiramente, Luna faz um levantamento de como o conceito surge em inúmeras pesquisas: i) como um contrassenso: caso se categorizem todos os indivíduos como vulneráveis, como serão escolhidos aqueles que realmente estão em situação de vulnerabilidade? Todos somos vulneráveis em um momento ou outro da vida, mas há diferentes tipos de vulnerabilidade e diferentes momentos de vulnerabilidade; ii) como compaixão: adjetivar indivíduos como vulneráveis é um caminho para considerá-los dignos de pena (aqui caberia uma observação, por exemplo, sobre o como a televisão, quer em seus produtos jornalísticos, quer em produtos "de diversão", romantiza a pobreza, a subalternidade, o periférico, e, em muitas situações, as causas LGBTI, as causas feministas, as pautas da negritude/branquitude); iii) o estereótipo: certa crítica que lida com a vulnerabilidade aponta que o adjetivo, em vez de promover igualdade, carrega o risco de apontar o indivíduo como um sujeito "etiquetado", o que seria algo negativo, e isso ocorre com o morador da favela, o encarcerado, as mulheres trans do mercado sexual, os indivíduos em situação de trabalho análogo à escravidão; iv) a proteção insuficiente: que ocorre quando o indivíduo é considerado vulnerável, mas não se encontram respostas para seus problemas, e isso ocorre na Medicina e no Direito, a escolha de quem deve receber auxílio e nas escolhas complexas de bolsas de estudo etc. (LUNA, 2008).

Veja-se:todas essas realidades são possíveis. Nãosão excludentes ou includentes; podem ser coexistentes, mas requerem uma abordagem mais profunda. Podemos dizer que a mulher é um sujeito social em constante estado de vulnerabilidade. $\mathrm{Na}$ rua, corre mais riscos que os homens; no trabalho, ganha menos e está sem situação de desvantagem; não encontra espaço nas igrejas (com exceções talvez nas religiões de matriz africana), no esporte (onde recebem menos aportes financeiro e menos apoio, e ainda correm o risco de serem sexualizadas), e mesmo no meio acadêmico, onde, por certa lógica, deveria haver mais liberdade e receptividade; e assim é no meio jurídico (bastando-se, por exemplo, verificar o número de desembargadoras no Brasil frente ao número de homens desembargadores, e julgadores monocráticos, e ministros do Supremo), no meio médico, no meio de pesquisa etc. Ou seja, onde há o ser mulher, há o sujeito vulnerável.

No entanto, assim como o termo "sociedade" não define cada indivíduo (acima, citamos o comentário de Sloterdjik) em suas particulares, o termo "ser mulher" também não. Há mulheres negras, mulheres indígenas, mulheres lésbicas, mulheres quilombolas, assim como há mulheres em situação de rua e ricas, mulheres que sofrem violência física, moral, financeira. Há mulheres arrimo de família em todas as classes, mas as mulheres arrimo de família que moram em periferias sofrem mais com a violência da polícia, a violência das milícias e a violência das próprias condições de moradia. Então, como equacionar isso tudo e encontrar respostas para diferentes situações de vulnerabilidade? Pensar que as vulnerabilidades são coexistentes e 
possíveis, como camadas (capas), que podem ser vistas, analisadas, retiradas uma a uma, traz certo conforto teórico assim como para uma prática de ações. Não se propõe comparações que a nada levam, como dizer que uma mulher trans seria considerada menos ou mais vulnerável que outras mulheres (embora saibamos os riscos que as mulheres trans correm todos os dias de sua vida), ou que as mulheres não cis seriam menos ou mais vulneráveis que outras mulheres, que as mulheres negras seriam mais ou menos vulneráveis que outras, mas que há diferenças entre ser uma mulher branca e ser uma mulher negra, ser cis ou não, ser trans ou não, ser da periferia das cidades ou dos centros, pertencer a um grupo religioso ou não, e assim por diante. A metáfora das camadas permite uma intersecção interessante e ainda a possibilidade de, no caso de ajuda (financeira, psicológica, jurídica), que as camadas sejam removidas uma a uma. Ela permite, sem o jogo falso da pena, da compaixão, investigar as reais situações de vida de cada mulher.

Não se trata, portanto, nem de rotular, etiquetar, enxergar o outro com compaixão ou, ainda, e o que é mais grave, transformar todos os indivíduos como seres idênticos, enfrentando os mesmos problemas. Investigar as camadas possibilita ações (legais, médicas, de auxílio emergencial) em níveis distintos e éticos.

Já nos anos 1970-80, a teórica canadense Dorothy Smith trazia à tona uma situação que até então parecia nova: o fato de que grande parte das questões sobre a mulher não levava em consideração a real situação da mulher, pois muito se pensava na mulher fora de casa (trabalho, estudo, outros ambientes) mas não na mulher que tinha uma segunda ou terceira jornada de trabalho. Por isso, a pesquisadora desenvolveu um estudo sobre o papel da mulher "dentro de casa, como mãe e dona de casa":

[...] desenvolver uma sociologia para mulheres/pessoas pautada pela ideia de partir do ponto de vista de uma dona de casa e mãe nas realidades de seu cotidiano e ancorar uma investigação do social em realidades concretas do cotidiano e das ações cotidianas. (SMITH, 2007) ${ }^{3}$

Talvez para os pesquisadores e pesquisadoras de hoje isso possa parecer óbvio em demasia, mas, naquele momento, partir das experiências do cotidiano trouxe um outro ponto de vista, a partir do qual (dentre tantas pensadoras e pensadores) foi possível construir novos discursos e novas práticas.

Atualmente, os discursos decoloniais ou descoloniais ganham corpo e espaço nas discussões acadêmicas (veja-se o exemplo de Lugones e outras tantas pensadoras e pensadores). Então, pensar a situação da mulher com "camadas de vulnerabilidade" é mais uma possibilidade de encontrarmos respostas para a terrível situação da mulher no mundo contemporâneo.

\footnotetext{
${ }^{3}$ [...] developing a sociology for women/people starded with the idea of beginning in the standpoint of a housewife and mother in the actualities of her everyday world and anchoring an investigation of the social in concrete actualities of the everyday and of everyday doings (SMITH, 2007).
} 


\section{CONCLUSÃO}

Lidar com palavras e conceitos é um dos grandes entraves dos estudos das áreas humanas. Há não somente uma situação de uso vocabular no interior da língua, quando se agrupam saberes numa franca categorização - e assim falamos em Sociologia, em Antropologia, em História, em Linguística, sem perceber que tais áreas dialogam muito mais que se afastam - como também um entrave quando a situação é de tradução de um vocábulo, de um conceito. Desse modo, cabe perguntar se devemos usar "negro" ou "preto" e se, ao usarmos tais especificadores linguísticos, não estaremos invadindo um território do discurso, um lugar em que o uso é natural e um recurso não meramente vocabular e sim político. Em outras situações, como citado acima, uma palavra de uso tão comum como "sociedade" merece atenção, pois que relativa, quando pensamos na própria diversidade, que é justamente uma das características das sociedades. E haverá problemas desses teores nos estudos queer ou nos estudos indígenas, no Direito ou na Filosofia.

A explicação anterior se deve ao fato de que, aqui, precisamos das palavras "mulher", "feminismo", "feminista", assim como das expressões "da mulher", "da luta das mulheres", "dos direitos da mulher". Como não existe em português um adjetivo como "mulhérico/a", precisamos contornar a situação para não cairmos na atração delicada do uso de "feminino" ou "feminil" (palavra mais rara), muitas vezes sem o valor que as demais expressões carregam no interior das lutas feministas. Florencia Luna trata da questão da vulnerabilidade, num contexto mais amplo, o da ética da pesquisa. Levando em conta todo o quadro que descrevemos nas duas primeiras partes deste texto, mas tendo em mente que cada mulher é uma mulher diferente da outra, mesmo fazendo parte de uma mesma sociedade ou de um grupo, acreditamos que a "metáfora das camadas" pode ser uma ferramenta bem eficaz na lida das complexidades da situação da mulher. Como cada indivíduo tem sua trajetória, precisemos de ferramentas para lidar, de modo ético, com as diferenças e as divergências entre os sujeitos.

Vivemos o capitalismo tardio, o neoliberalismo (e hojejá se fala em ordoliberalismo), vivemos a pós-modernidade, o pós-humano, a hipermodernidade, o mundo líquido, o antropoceno? Seja a abordagem que for, temos algo em comum: um mundo ainda dominado pelo discurso masculinista, pelo eurocentrismo branco e pelo poder do mercado. Encontrar respostas para essas dificuldades é dever de todo pesquisador e pesquisadora. Atrair para o centro das pesquisas outros grupos - médicos, operadores do direito, políticos, clérigos - é um dos nossos grandes desafios.

\section{REFERÊNCIAS}

BERTHOLDI, Juliana. Propostas de redação aos planos nacionais de ação latino-americanos desde uma análise feminista. 2021. Dissertação (Mestrado em Direito) - Pontifícia Universidade Católica do Paraná, Curitiba, 2021.

BOURDIEU, Pierre. A dominação masculina. Tradução de Maria Helena Kühner. Rio de Janeiro: Bertrand Brasil, 2012. 
DAVIS, Natalie Zemon. Nas margens: três mulheres do século XVII. Tradução de Hildegard Feist. São Paulo: Companhia das Letras, 1997.

FEDERICI, Silvia. Calibã e a bruxa: mulheres, corpo e acumulação primitiva. Tradução Coletivo Sycorax. São Paulo: Elefante, 2017.

HELLER, Agnes. 0 cotidiano e a história. 4. ed. Tradução de Carlos César Coutinho e Leandro Konder. Rio de Janeiro: Paz e Terra, 1992.

HOOKS, bell. Olhares negros: raça e representação. Tradução de Sthefanie Borges. São Paulo: Elefante, 2019.

LUNA, Florencia. Vulnerabilidad: a metáfora de las capas. Jurisprudencia Argentina, IV, Fascículo 1, p. 60-67, 2008. Disponível em: http://www.saludcapital. gov.co/Capacitaciones $\% 20 \% 20$ Comit $\% 20$ de $\% 20$ tica $\% 20$ para $\% 20 l a \% 20$ Investigacin/6\%20Sesión\%2016\%20julio\%202014/Luna F[1]. Vulnerabilidad la metafora de las capas.pdf. Acesso em: 30 abr. 2021.

SMITH, Dorothy. Collection le sciences sociales contemporaines. 2007. Disponível em: http://classiques.uqac.ca/contemporains/smith dorothy/smith dorothy photo/smith dorothy photo.html. Acesso: 30 abr. 2021.

SLOTERDIJK, Peter. Estrés y liberdad. Buenos Aires: Egodot, 2017. VERGĖS, Françoise. Um feminismo decolonial. Tradução de Jamile Pinheiro Ribas e Raquel Camargo. São Paulo: Ubu, 2020. 